\title{
Magnolia wufengensis 'Jiaohong No. 2': A New Magnolia Cultivar with Bright Red Lotus-shaped Flowers
}

\author{
Qun Yin, Xiaodeng Shi, and Zhonglong Zhu
}

Beijing Advanced Innovation Center for Tree Breeding by Molecular Design, National Engineering Laboratory for Forest Tree Breeding, Beijing Forestry University, Beijing, China 100083; and Magnolia wufengensis Research Center, Beijing Forestry University, Beijing, China 100083

\author{
Ziyang Sang \\ Forestry Science Research Institute of Wufeng County, Wufeng, Hubei \\ Province, China 443400
}

\section{Guijuan Du}

Jiawang Branch of Xuzhou Natural Resources and Planning Bureau, Xuzhou, Jiangsu Province, China 221011

\section{Luyi Ma}

Beijing Advanced Innovation Center for Tree Breeding by Molecular Design, National Engineering Laboratory for Forest Tree Breeding, Beijing Forestry University, Beijing, China 100083; and Magnolia wufengensis Research Center, Beijing Forestry University, Beijing, China 100083

\section{Zhongkui Jia \\ Magnolia wufengensis Research Center, Beijing Forestry University, Beijing, China 100083; and Key Laboratory for Silviculture and Conservation of the Ministry of Education, College of Forestry, Beijing Forestry University, Beijing, China 100083}

Additional index words. breeding, grafting, ornamental tree, red flower

The new cultivar Magnolia wufengensis 'Jiaohong No. 2' was bred from the excellent individuals of $M$. wufengensis var. multitepala L.Y. Ma et L.R. Wang (Ma et al., 2006) by grafting. In 2004, the parent plant of 'Jiaohong No. 2' was discovered in a natural secondary forest at an elevation of $1700 \mathrm{~m}$ $(5577 \mathrm{ft})$ in Wufeng County, Hubei Province, Central China. Because of its beautiful tree figure and lotus-shaped, bright red [(RHS 54A), Royal Horticultural Society (RHS) Color Chart, 2007] flowers, it is considered perfect for a garden plant and has considerable ornamental and economical value. With the ongoing efforts of L.Y. Ma, Z.K. Jia, and Z.L. Zhu, those phenotypes have been preserved and propagated vegetatively via grafting. In July 2014, the State Forestry Administration Office for the Protection of New Varieties of Plant approved the release of the new cultivar $M$. wufengensis 'Jiaohong No. 2', which is under patent protection by

Received for publication 19 July 2021. Accepted for publication 16 Oct. 2021.

Published online 17 December 2021.

Q.Y. and X.S. contributed equally to this work.

Z.J. and L.M. are the corresponding authors. E-mail: jiazk@163.com or maluyi@bjfu.edu.cn. This is an open access article distributed under the CC BY-NC-ND license (https://creativecommons. org/licenses/by-nc-nd/4.0/).
Beijing Forestry University (patent no. 20140050). In the same year, the cultivar was authorized as an elite forest tree variety of Hubei Province (certificate no.: S-SV-MW013-2013). On 31 Mar. 2021, it was validated as a national elite forest tree variety of China (certificate no.: Guo S-SV-MW-004-2020). 'Jiaohong No. 2' has considerable ornamental value owing to its bright red (RHS 54A) flowers; additionally, it has an extremely economical value because of its excellent wood characteristics (strong, straight texture) can be widely used in furniture, drawing boards, and joinery (Duan et al., 2019). In addition, it has appreciably ecological value and is widely used in mountain afforestation, urban greening, and ecological restoration projects. Furthermore, natural plant essential oils rich in sterols, n-alkanes, and terpenes can be extracted from its flowers. In summary, breeding and propagating of 'Jiaohong No. 2' has not only increased the diversity of ornamental plant species in the Magnoliaceae family and economic benefits, but also preserved $M$. wufengensis as a kind of scarce plant resource.

\section{Origin}

The cultivar 'Jiaohong' is named for its flower color, which presents the vibrant red color (RHS 54A) on the abaxial side and pink color (RHS 54C) on the adaxial side of the tepals ('Jiaohong' means delicate red flowers in Chinese). With an origin in a secondary forest in Wufeng County, 'Jiaohong No. 2' was first propagated and domesticated in 2004 in Changchongzi Town, Xian'an District (the altitude is $\approx 900 \mathrm{~m}$ ), Xianning City, Yichang City (the altitude is $\approx 70 \mathrm{~m}$ ), Hongshan District, and Wuhan City (the altitude is $\approx 50 \mathrm{~m}$ ) in Hubei Province. Grafting is the most appropriate method for propagating this cultivar due to the relatively restricted number of parent trees, significantly self-infertility, and low seed production. In Sept. 2004, a team led by Luyi Ma collected branches from M. wufengensis and performed grafting by the single-bud ventral method on 2-year-old Magnolia denudata at the testing ground in Xian'an District. In Fall 2006 to 2008, branches from the surviving grafted plantlets were successively collected, and the secondand third-generation survival rates were over 90\%. In Aug. 2007, branches from the wild parent tree were collected and grafted onto $M$. denudata rootstocks with a diameter at breast height $(\mathrm{DBH})$ of $4 \mathrm{~cm}$ at the Changchongzi Experimental Base. In Fall 2008 to 2010, branches were collected from surviving grafted plantlets, and the second-and thirdgeneration survival rate was above $95 \%$. In Fall 2009, 200 grafted seedlings of this species were introduced to the Hongshan Experimental Base. In Spring 2008, plantlets in Xian'an began to flower, and in Spring 2009, plantlets in Changchongzi began to flower. In 2010, successfully grafted plantlets at the above two experimental sites started to flower, and in Spring 2012, 200 grafted plantlets in Hongshan began to flower. Thus, after the initial propagation, it took 2-4 years for the plantlets to bloom. The second-generation plantlets propagated by grafting flowered after 1-2 years. All of the plantlets displayed the same genetic traits as the parent tree. This is a sign of successful propagation of 'Jiaohong No. 2'.

\section{Description and Performance}

'Jiaohong No. 2' is expected to reach a mature height of 15-20 m (Fig. 1A) according to its tall and straight growth habit. It is a type of hysteranthous deciduous plant blooming in early spring with a rich profusion, red (RHS 54A), fragrant, lotus-shaped flowers; the flowers are solitary and erect at the branch tips (Fig. 1B). The perianth is composed of 12 (occasionally 13 or 14 ) tepals, and all tepals are obovate-strip, narrower. Flower color was described according to the RHS Color charts, fifth edition. The abaxial tepals are bright red (RHS 54A, Fig. 1C), the adaxial tepals are pink (RHS 54C, Fig. 1D). The tepal color is relatively stable from year to year under the changing climate and site conditions. The flowering periods in Yichang of Hubei Province, Beijing, Dali of Yunnan Province, and Nanyang of Henan Province are 8-29 Mar., 11-25 Mar., 23 Dec.-23 Feb., and 10-29 Mar., respectively. 

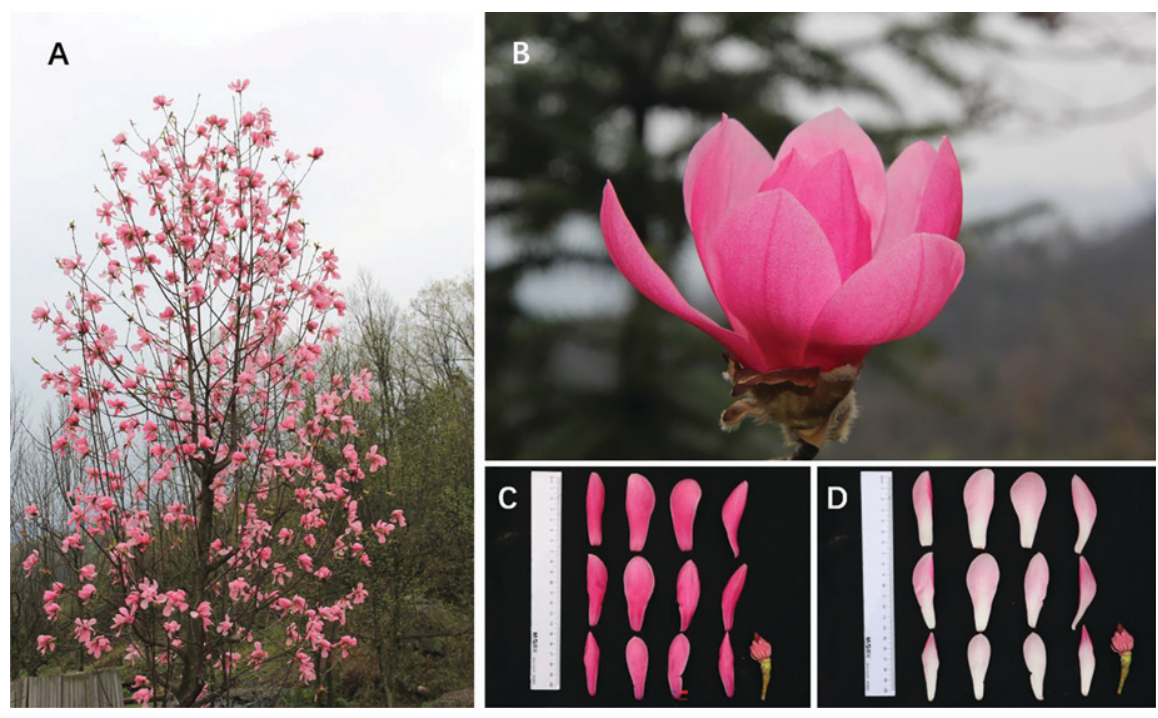

Fig. 1. Morphological characters of Magnolia wufengensis 'Jiaohong No. 2' flowers: (A) flowers on the tree, (B) individual flower, (C) abaxial side of tepals, and (D) adaxial side of tepals.
Leaves are alternate or spirally arranged on the branches and dark green adaxially and light green abaxially, glossy, thick blades, and clear veins. Leaves are obovate-elliptic and entire, and leaf apex acute or obtusely rounded, tapering to cuneate below the middle. The annual branches are soft green from April to July, with a few grayish-white halo spots that gradually increase beginning in late July, and by September and October are covered with gray halo spots. The lenticels are round with tiny inconspicuous white spots.
The distinctiveness of $M$. wufengensis 'Jiaohong No. 2' can be demonstrated by a comparison with $M$. wufengensis 'Jiaolian' (Duan et al., 2020), the same original cultivar in M. wufengensis (Table 1). These two cultivars differ in tepal and leaf morphology characters. Specifically, 'Jiaohong No. 2' has brighter color tepals.

\section{Dissemination of Cultivars}

'Jiaohong No. 2' is best suited to acidic to neutral, fertile, and well-drained soils. Experiments have shown that it can grow normally at
Table 1. Morphological differences between Magnolia wufengensis 'Jiaohong No. 2' and M. wufengensis 'Jiaolian'.

\begin{tabular}{|c|c|c|}
\hline Characters & M. wufengensis 'Jiaohong No. 2' & M. wufengensis 'Jiaolian' \\
\hline Tepal color & $\begin{array}{l}\text { Bright red (RHS 54A) outside, pink } \\
\text { (RHS 54C) inside }\end{array}$ & $\begin{array}{l}\text { Purplish red (RHS 64D) outside, } \\
\text { pinkish-purple (RHS 75C) inside }\end{array}$ \\
\hline Tepal number & $12(-14)$ & $18-20(-24)$ \\
\hline Tepal shape & Obovate-strip, narrower & Obovate-elliptic \\
\hline Leaf morphology & $\begin{array}{l}\text { Broad, rounded, and slightly } \\
\text { concave at the apex, smooth }\end{array}$ & $\begin{array}{l}\text { Elliptic, with rounded and broad } \\
\text { apices and broad cuneate bases }\end{array}$ \\
\hline Flower bud morphology & Densely white villose & Densely white villose \\
\hline
\end{tabular}

an extremely low temperature of $-16.7^{\circ} \mathrm{C}$ and an extremely high temperature of $39.7^{\circ} \mathrm{C}$. To date, it has been introduced to 45 cities in 22 provinces throughout China, with an average survival rate of $83.24 \%$. The optimum survival zone for this cultivar is in Central China, southwestern China, and southern China, in sites with a warm temperate, subtropical, or tropical climate.

'Jiaohong No. 2' propagates primarily by grafting. The rootstock can be healthy $M$. wufengensis seedlings, Magnolia biondii, and $M$. denudata, and single-bud grafting in fall (southern China) or spring (northern China) is the optimal method.

\section{Availability}

M. wufengensis is usually used as a street, landscape, and afforestation tree and can even be made into indoor bonsai through dwarfing techniques.

The owners of the cultivar 'Jiaohong No. 2' are Beijing Forestry University (Beijing, China), Three Gorges University (Yichang, China), and Wufeng Boling Magnolia Technology Development Co., Ltd. (Yichang, China). Field-planted breeding material for 'Jiaohong No. 2' is maintained by Wufeng Boling Magnolia Technology Development Co., Ltd. Requests for the cultivar should be submitted to the company homepage (http://www.wfhhyl. $\mathrm{com} /$ ) or the coauthor Dr. Ziyang Sang (E-mail: sangziyang@21cn.com).

\section{Literature Cited}

Ma, L.Y., L.R. Wang, S.C. He, X. Liu, and X.Q. Wang. 2006. A new variety of Magnolia (Magnoliaceae) from Hubei, China. Bull. Bot. Res. 26:517-519, https://doi.org/10.3969/j.issn.16735102.2006.05.002.

Duan, X., Z. Zhu, Z. Sang, F. Chen, and L. Ma. 2020. Magnolia wufengensis 'Jiaolian': A new magnolia cultivar with lotus-shaped flowers. HortScience 55(11):1869-1870, https://doi.org/ 10.21273/HORTSCI15348-20.

Duan, X., C. Cai, Y. Yang, F. Chen, Z. Sang, and L. Ma. 2019. Fall ethephon application enhances the freezing tolerance of Magnolia wufengensis during overwintering. Forests 10(10):868, https:// doi.org/10.3390/f10100868.

Royal Horticultural Society Colour Chart. 2007. 5 th ed. Royal Horticultural Society, London. 